\title{
How many implants are needed for mandibular full-arch rehabilitation?
}

\author{
Karina Giovanetti ${ }^{1}$ (D) Ricardo Armini Caldas ${ }^{2}$ (D), Paulo \\ Henrique Ferreira Caria ${ }^{3, *}$ (i)
}

${ }^{1}$ Department of Biosciences, Piracicaba Dental School, University of Campinas, São Paulo, Brazil.

${ }^{2}$ Department of Prosthodontics and Periodontology, Piracicaba Dental School, University of Campinas, São Paulo, Brazil.

${ }^{3}$ Department of Structural and Functional Biology, Institute of Biology, University of Campinas, São Paulo, Brazil
Corresponding author:

Paulo Henrique Ferreira Caria Department of Structural and Functional Biology, Institute of Biology, University of Campinas, Monteiro Lobato St, 255 - Zip code: 13083-862 Campinas, São Paulo, Brazil. Phone/fax;+55193521-6184 E-mail address: phcaria@unicamp.br

Received: April 16, 2020

Accepted: August 31, 2020
Aim: To analyze the stress distribution at the peri-implant bone tissue of mandible in full-arch implant-supported rehabilitation using a different number of implants as support. Methods: Three-dimensional finite element models of full-arch prosthesis with 3, 4 and 5 implants and those respective mandibular bone, screws and structure were built. ANSYS Workbench software was used to analyze the maximum and minimum principal stresses (quantitative analysis) and modified von Mises stress (qualitative analysis) in peri-implant bone tissue after vertical and oblique forces $(100 \mathrm{~N})$ applied to the structure at the cantilever site (region of the first molars). Results: The peak of tensile stress values were at the bone tissue around to the distal implant in all models. The model with 3 implants presented the maximum principal stress, in the surrounding bone tissue, higher ( 14\%) than the other models. The difference of maximum principal stress for model with 4 and 5 implants was not relevant $(\sim 1 \%)$. The first medial implant of the model with 5 implants presented the lower (17\%) stress values in bone than model with 3 implants. It was also not different from model with 4 implants. Conclusion: Three regular implants might present a slight higher chance of failure than rehabilitations with four or five implants. The use of four implants showed to be an adequate alternative to the use of classical five implants.

Keywords: Dental implants. Finite element analysis. Mouth rehabilitation. Prosthodontics. 


\section{Introduction}

The implant-supported prostheses are a successful form of treatment, presenting a high survival rate and favorable biomechanical conditions ${ }^{1}$. Among the possibilities of treatment for edentulous patients, the full-arch fixed prosthesis presents better stability and masticatory efficiency when compared to complete denture or overdentures ${ }^{2}$.

The Brånemark Novum concept (oral implant protocol) indicates the use of three wide implants to support a full-arch fixed prosthesis in the edentulous mandible ${ }^{3}$. From this, technical variations were developed by changing the size, position, and numbers of implants ${ }^{4}$. The success of new protocols depends on several factors, such as implant inclination, bone quality, bone quantity, and distribution of masticatory loads to the prosthetic system (prosthesis, framework, and prosthetic components) 5 . As an alternative to improve the biomechanical behavior, it has been suggested to increase the implant diameter and tilting the distal implants to reduce the cantilever length6. Also, the stress distribution in the periimplant bone is directly related to occlusion, masticatory force, number, and position of the implants ${ }^{7}$.

Short and medium-term clinical reports have demonstrated the successful use of four implants, even inclined or paralle ${ }^{8}$. Thus, simplified protocols become cheaper and provide less morbidity to patients. Full-arch rehabilitation in the edentulous mandible supported by 3,4 or 5 regular implants has been described by several studies showing high success rates $^{9,10}$. However, long-term studies are necessary to evaluate the biological complications, survival rates, implant failures, and technical complications of these rehabilitations ${ }^{9}$.

To understand the bone behavior in rehabilitations with dental implants, several studies with different methods have been performed. The use of finite element method (FEM) allows investigating the biomechanical behavior on specific three-dimensional models, making it possible to predict and quantify the stresses induced throughout the biological system ${ }^{11}$. Therefore, this study aimed to evaluate the stresses transmitted to the peri-implant bone tissue in 3D finite elements models with three, four, or five dental implants built for the oral rehabilitation of the mandible full-arch fixed prosthesis.

\section{Materials and methods}

Three-dimensional models of full-arch prosthesis were constructed, varying from 3 to 5 implants (Figure 1).

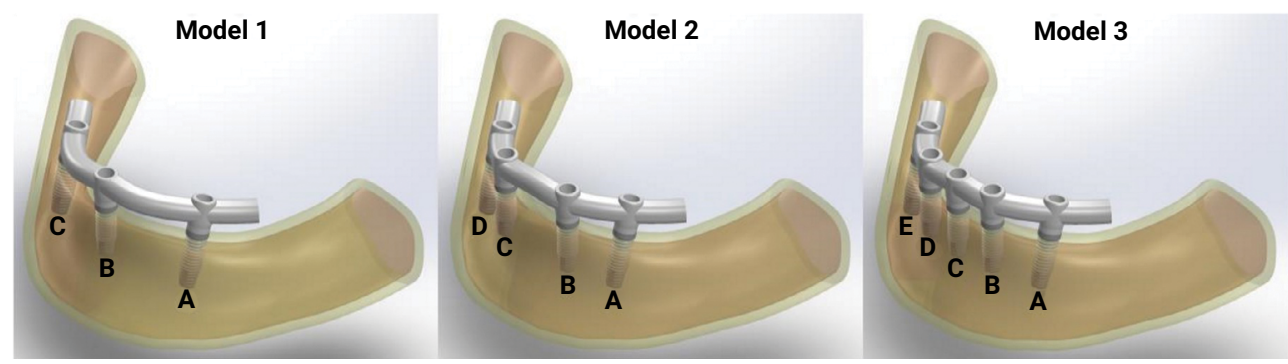

Figure 1. Three-dimensional computer models of three full-arch prosthesis evaluated, varying from 3 to 5 implants. 
The groups: Model 1: total of 3 implants, two positioned $5 \mathrm{~mm}$ mesial to each mental foramen (15 degrees angulated to distal) and the third implant vertically at midline; Model 2: total of 4 implants, two positioned $5 \mathrm{~mm}$ mesial to each mental foramen (15 degrees angulated to distal) and two implants vertically, $9 \mathrm{~mm}$ from midline to each side; Model 3: total of 5 implants, two positioned $5 \mathrm{~mm}$ mesial to each mental foramen (15 degrees angulated to distal), two implants vertically $9 \mathrm{~mm}$ from midline and one implant vertically at midline. In all models, the framework was $4 \mathrm{~mm}$ distant from the alveolar process, with a cross section of $4.3 \mathrm{~mm}$ width x $3.6 \mathrm{~mm}$ height, and $8 \mathrm{~mm}$ in each side cantilever. The bone geometry was constructed based on an edentulous mandible of an approximately 60-year-old man from a Cone Bean computerized tomography (images with $0.25 \mathrm{~mm}$ range) Mimics 17.0 (Materialise, Leuven, Belgium). The desired bone density was selected to create the image mask and then regularized the remaining alveolar ridge of the mandible. Furthermore, the model was simplified by removing mandibular ramus, with no influence on the results.

Also, models of external hexagonal cylindrical implants with dimensions of $\varnothing 4.1 \mathrm{~mm}$ x $11.5 \mathrm{~mm}$ in length Nobel Biocare (Yorba Linda, CA, USA), screws, prosthesis framework and complete assemblies were made in the software SolidWorks ${ }^{\circledR}$ (Dassaul Systeme, Waltham, MA, USA). The 3D models are available at the Supplementary data (file format: .OBJ). The 3D models were imported to software ANSYS Workbench ${ }^{\circledR}$ 14, (Canonsburg, PA, USA). All the materials were set to homogeneous, isotropic and linear elastic. The material properties are shown in Table 1, as previous studies $^{12}$. In addition, the contact between implants and framework was set to frictional $(\mu=0.3)^{13}$ and all other contacts between different materials were set to be bonded. Then, the meshes were set as 10-node tetrahedrons and refined to a point where it does not considerably affect the obtained results.

The mesh was checked for element quality and refined in the regions of interest, resulting in about 400,000 elements and 600,000 nodes per model. The posterior surface of mandible was set to fixed (zero degrees of freedom). The mechanical loading was performed with vertical or oblique ( $45^{\circ}$ to vestibular) forces of $100 \mathrm{~N}$ applied at the framework's cantilever in different analysis, simulating bite forces ${ }^{14}$.

The data of the maximum and minimum principal stresses (quantitative analysis) and modified von Mises stress (qualitative analysis) were realized by the ANSYS Worbench ${ }^{\circledR} 14$ software in the 3D finite element models ${ }^{15}$.

\section{Results}

At surrounding bone tissue of implant $A$, the model 1 presented the maximum principal stress $\sim 14 \%$ higher than model 2 and 3 (Table 1). The maximum principal stress difference for model 3 to 2 was not relevant ( 1\%). At implant B, the model 3 present the lower stress values in bone, being $17 \%$ lower than model 1 , and also not relevant different from model 2 (Table 1). 
Table 1. Comparison of vertical loading (maximum and minimum principal stress) to implant $A$ and $B$, on the three full-arch prosthesis evaluated.

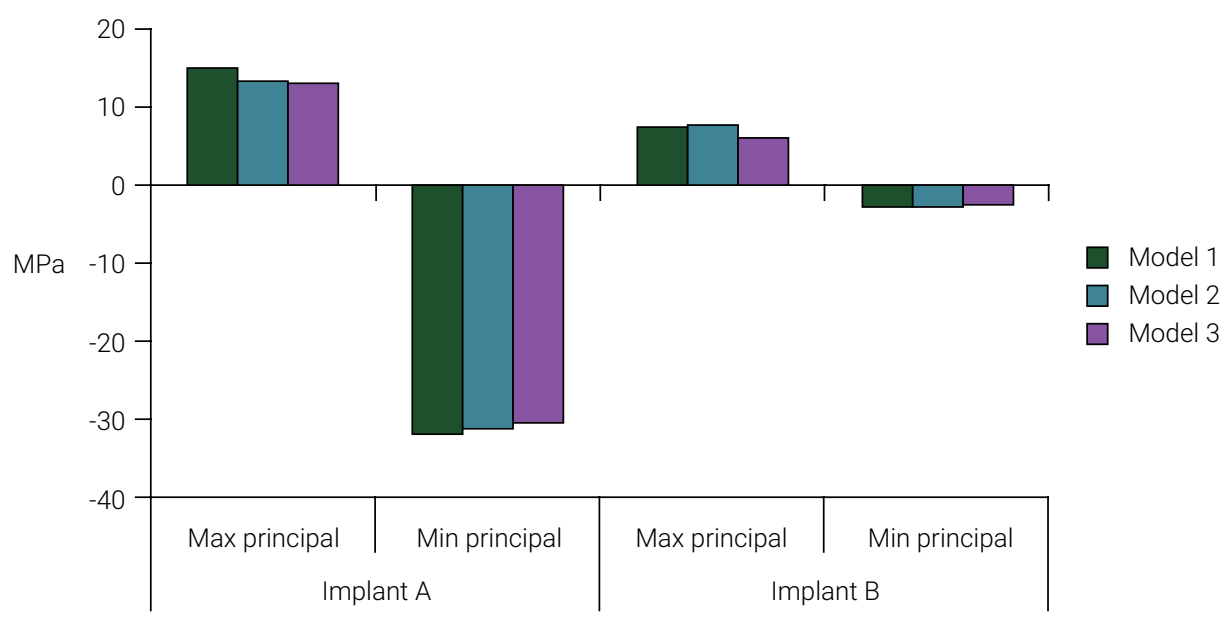

The compressive stress values (minimum principal stresses) at vertical loading showed inverse relationship to number of implants. However, these differences of stress values were not relevant $(\leq 1 \%)$ (Table 1).

For oblique loading, model 1 presented minimum principal stress $10 \%$ higher than model 2 and 3 at implant $A$ (Table 2).

Table 2. Comparison of oblique loading (maximum and minimum principal stress) to implant $A$ and $B$, on the three full-arch prosthesis evaluated.

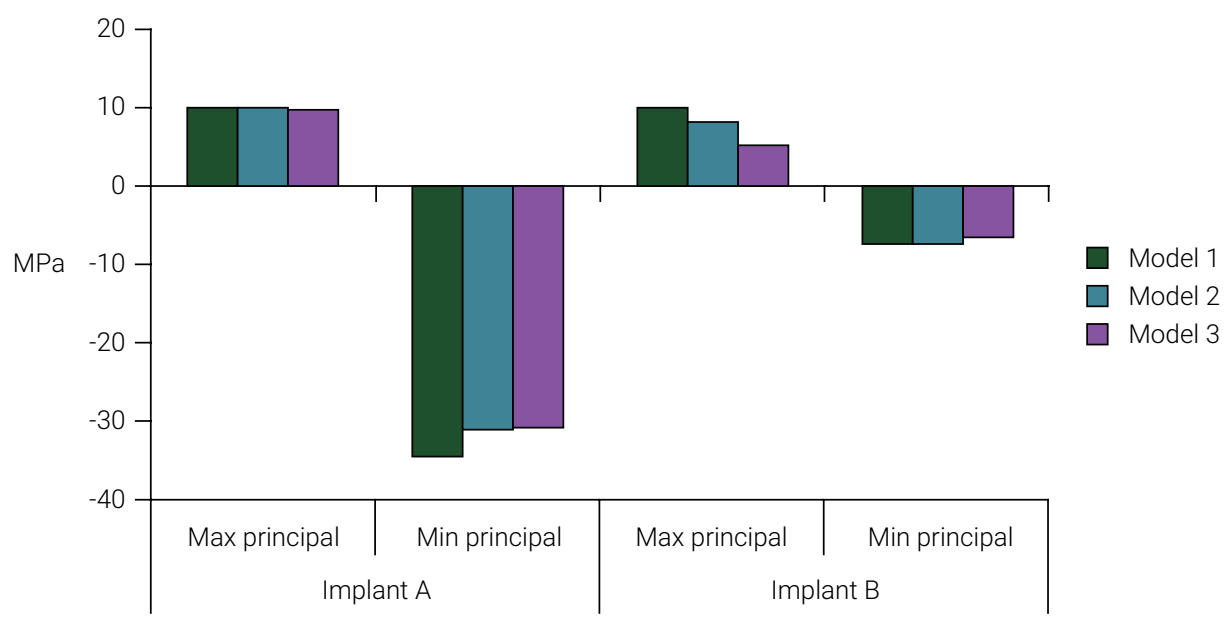

No relevant differences were observed for maximum principal stress at implant $A$. The stress field presented by modified von Mises indicates a similar behavior around implant A for all models (Figure 2). 

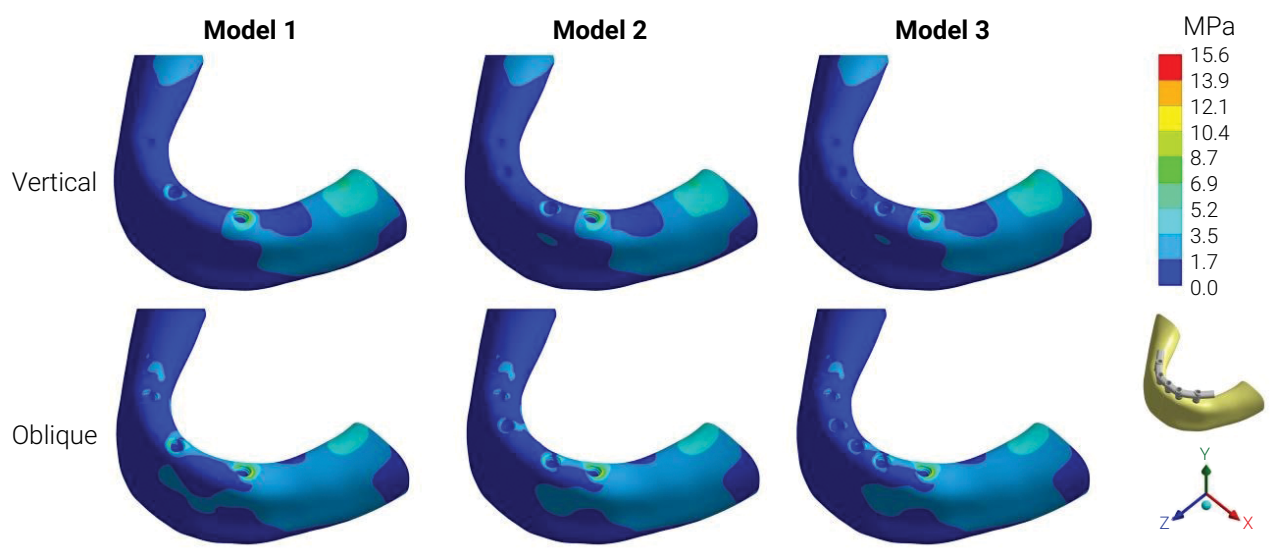

Figure 2. The stress field by vertical and oblique loading, represented by von Mises analysis, around implant A, for the three models of full-arch prosthesis evaluated.

The highest values were at distal side of implant A for vertical loading and directed to buccal side for oblique loading. As the higher stress values concentrated at implant $A$ and $B$, the implants $C, D$ and $E$ were not included in the comparison. For a better understanding of stress location at bone tissue (tensile and compressive), the figure 3 indicates the movements of the cantilever after the mechanical loading. The vectors indicate the movement direction and magnitude.
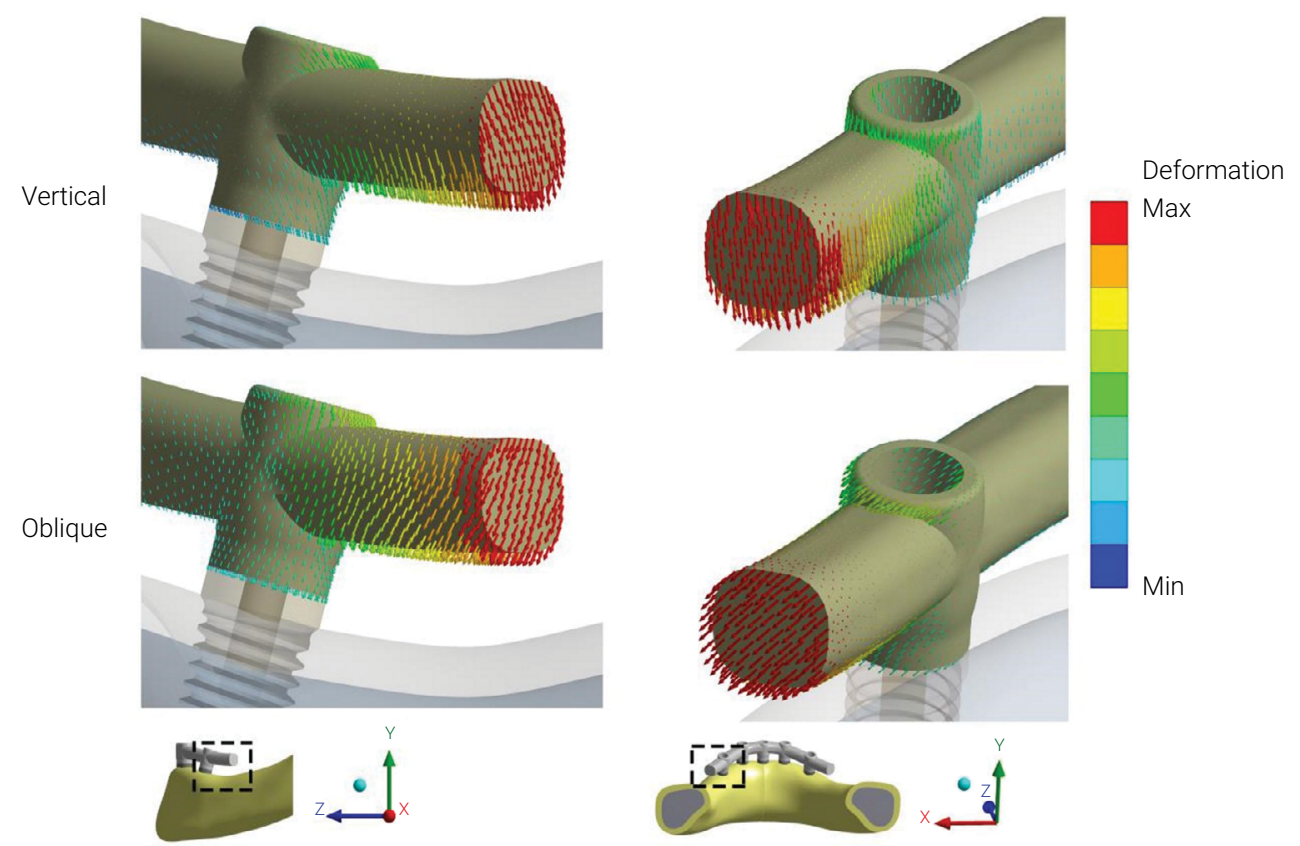

Figure 3. The deformation of the cantilever during the vertical and oblique loading. The vectors indicate the movement direction and the respective magnitude. 


\section{Discussion}

This study evaluated the peri-implant bone stresses with a different number of implants supporting a full-arch oral rehabilitation. The results showed different stresses values for the studied cases. The decreasing in the number of implants used for fullarch rehabilitation has been subject to laboratory and clinical studies ${ }^{9,16,17}$, aiming to minimize treatment costs and patient morbidity ${ }^{8}$. Literature data have shown high success rates for total rehabilitations with 3, 4 and 5 dental implants ${ }^{8-10,17}$. In an observational study with 33 patients with an 18-month follow-up of a complete fixed mandibular prosthesis supported by three implants, an adequate option was developed with peri-implant bone loss that has been described for prostheses of the same type supported by larger numbers of implants ${ }^{9}$. In a systematic review, it was observed survival rate for more than 24 months of $99.8 \%$ in full arch 4 mandibular implants ${ }^{10}$ However, there is a lack of sufficient long-term data with follow-ups of at least 5 years to evaluate the biological complications, survival rates, implant failures, and technical complications of these rehabilitations with three implants ${ }^{9,18}$. Also, some studies concerns about the influence of reducing implants' number in the survival rate of prosthetic components ${ }^{9,19}$. The present study did not evaluated the influence of reduced number of implants at prosthetic components and its long-term consequence. Nevertheless, it is reported that the use of a lower number of implants could overload the prosthetic components, resulting in higher rates of screw loosening and leading to a larger number of follow-up appointments ${ }^{17}$.

According to the literature ${ }^{17}$, the tensile and compressive stresses generated during function were not sufficient to immediately damage the bone, presenting stress values lower than ultimate compressive $(167 \mathrm{MPa})^{20}$ and tensile $(100 \mathrm{MPa})^{21}$ strengths. However, these stresses can be harmful at the long-term analysis ${ }^{9,19}$. In a full-arch rehabilitation, the greatest loads are received by the distal implants, regardless of the total numbers of implants ${ }^{22}$. In the present study, the stresses generated in the peri-implant bone (implant A) are in agreement with Silva-Neto et al. ${ }^{17}$; they reported that reducing the number from 5 to 3 implants relevantly increased the stress in the peri-implant bone.

In our study, during axial forces the rehabilitation with 3 implants showed higher tensile stresses ( $14 \%$ higher) at peri-implant bone tissue than other analyzed models.

The compressive stresses followed the same pattern, but with no relevant difference at stress values among models $(\leq 1 \%)$. Also, for oblique loading, the compressive stress was $10 \%$ higher at the model with three implants ${ }^{17}$. The stresses at implant B presented influence of the implant number, with the reduction of number of implants increasing the bone stress. The rehabilitation with 5 implants showed a tensile stress $17 \%$ lower than the 3-implant rehabilitation.

Our data did not present relevant differences between the use of four or five implants. Even with differences among models, all results were lower than critical for bone fracture, and lower than the stress in implant A. As the risk of implant failure is directly related to peri-implant stresses, the main concern relies at implant $A$. As one of the alternatives to number of implants, literature suggests that increasing in stresses provided by three regular implants could be avoided placing wider implants 3,17 . 
The results of this study suggest that it is not necessary to use of the traditional 5 implants to support a mandibular full-arch rehabilitation ${ }^{9,17}$. Other studies have demonstrated satisfactory success rates with the use of 4 implants for full-arch fixed mandibular prosthesis ${ }^{10,23}$.

A longitudinal study of the survival of all-on-4 implants in the mandible with up to 10 years of follow-up showed prostheses' survival rate was 99.2 percent and implant-related success rates 93.8 percent $^{23}$. Although studies have demonstrated satisfactory survival rates of full-arch prosthesis fixed by 3 implants ${ }^{9}$, the use of 4 implants is in general safer, since in case of loss of some implant other than the distal one, there will still be a favorable biomechanical condition, not requiring a new surgical procedure. Moreover, if the implant is lost after function, it is possible to use an existing prosthesis 8,10 .

The use of osseointegrated implants in Dentistry provides stability and comfort to denture wearers, especially in the mandibular $a^{2}{ }^{8}$. Implants are used as pillars and when exposed to excessive functional loading can transmit harmful stresses directly to the periimplant bone, which may cause failure in osseointegration ${ }^{8}$. Around two thousand implant options are available for any clinical situation. Studies about implants use have to be done to orientate the clinic procedures form dentists.

In vitro tests can be divided into surface analysis and mechanical assessment. Different methodologies can present results that dentists may find difficult to understand their clinical application. The in vitro testing has limitations, however, current evidence presents new analysis as scanning electron microscopy useful to inform about the implant surface topography. Atomic force microscopy, single-cell tests, 3D imaging, and gene expression tests also could be used to the assessment of cellular and physio-biochemical properties of the implants ${ }^{24}$. As well as 3D finite element analysis has been used in the evaluation of mechanical properties of dental implants, as on the distribution of stresses in bone regions and prosthetic components ${ }^{25}$. The FEM allows to evaluate similarly to what happens in vivo by specific three-dimensional models, enabling prediction and quantification of stresses induced by the entire system ${ }^{11}$. The FEM is a computational analysis with restrictions because it cannot reproduce some variables from the oral environment. The results obtained with that analysis can be useful to understand the behavior of prosthesis supported by implants, which could not be done in vivo.

In a study similar to ours ${ }^{26}$, the authors concluded that the greater amount of implants supporting a complete arch prosthesis, promotes less stress concentration during simulated loading, and that decreasing the number of implants in a rehabilitation is harmful. Further experimental studies and clinical trials should be performed to verify the effects of such arrangements on the longevity of this type of rehabilitation.

The present results suggest that full-arch rehabilitations in the edentulous mandible with 3 regular implants present a slightly higher chance to failure than rehabilitations with 4 or 5 implants because of the higher stress concentration presented in some analysis. The use of 4 implants presented promising results suggesting to be adequate substitute to the classical technique that uses 5 implants. In addition, 
further clinical long-term analyses are recommended as the literature suggests that the use of wider implants could bypass this problem of higher stresses with 3 implants.

\section{Conflicts of interest}

The authors declare that there is no conflict of interest regarding the publication of this paper.

\section{Acknowledgements}

The authors thank Prof. Altair Antoninha Del Bel Cury for providing the FEA facility.

\section{References}

1. Wennerberg A, Albrektsson T. Current challenges in successful rehabilitation with oral implants. J Oral Rehabil. 2011 Apr;38(4):286-94. doi: 10.1111/j.1365-2842.2010.02170.x.

2. Mendonca DB, Prado MM, Mendes FA, Borges TF, Mendonça G, Prado CJ, et al. Comparison of masticatory function between subjects with three types of dentition. Int J Prosthodont. 2009 Jul-Aug;22(4):399-404.

3. Brånemark PI, Engstrand P, Ohrnell LO, Gröndahl K, Nilsson P, Hagberg K, et al. Brånemark Novum: a new treatment concept for rehabilitation of the edentulous mandible. Preliminary results from a prospective clinical follow-up study. Clin Implant Dent Relat Res. 1999;1(1):2-16. doi: 10.1111/j.1708-8208.1999.tb00086.x.

4. Capelli M, Zuffetti F, Del Fabbro M, Testori T. Immediate rehabilitation of the completely edentulous jaw with fixed prostheses supported by either upright or tilted implants: a multicenter clinical study. Int J Oral Maxillofac Implants. 2007 Jul-Aug;22(4):639-44.

5. de Almeida EO, Rocha EP, Freitas AC, Freitas MM. Finite element stress analysis of edentulous mandibles with different bone types supporting multiple-implant superstructures. Int J Oral Maxillofac Implants. 2010 Nov-Dec;25(6):1108-14.

6. Bevilacqua M, Tealdo T, Pera F, Menini M, Mossolov A, Drago C, et al. Three-dimensional finite element analysis of load transmission using different implant inclinations and cantilever lengths. Int J Prosthodont. 2008 Nov-Dec;21(6):539-42.

7. Himmlová L, Dostálová T, Kácovský A, Konvicková S. Influence of implant length and diameter on stress distribution: a finite element analysis. J Prosthet Dent. 2004 Jan;91(1):20-5. doi: 10.1016/j.prosdent.2003.08.008.

8. Crespi R, Vinci R, Capparé P, Romanos GE, Gherlone E. A clinical study of edentulous patients rehabilitated according to the "all on four" immediate function protocol. Int J Oral Maxillofac Implants. 2012 Mar-Apr;27(2):428-34.

9. Rivaldo EG, Montagner A, Nary H, da Fontoura Frasca LC, Brånemark PI. Assessment of rehabilitation in edentulous patients treated with an immediately loaded complete fixed mandibular prosthesis supported by three implants. Int J Oral Maxillofac Implants. 2012 May-Jun;27(3):695-702.

10. Soto-Penaloza D, Zaragozí-Alonso R, Penarrocha-Diago M, Penarrocha-Diago M. The all-on-four treatment concept: Systematic review. J Clin Exp Dent. 2017 Mar 1;9(3):e474-88. doi: 10.4317/jced.53613.

11. Taddei F, Cristofolini L, Martelli S, Gill HS, Viceconti M. Subject-specific finite element models of long bones: An in vitro evaluation of the overall accuracy. J Biomech. 2006;39(13):2457-67. doi: 10.1016/j.jbiomech.2005.07.018. 
12. Spazzin AO, Costa AR, Correr AB, Consani RL, Correr-Sobrinho L, dos Santos MB. Effect of bar crosssection geometry on stress distribution in overdenture-retaining system simulating horizontal misfit and bone loss. J Biomech. 2013 Aug 9;46(12):2039-44. doi: 10.1016/j.jbiomech.2013.05.025.

13. Deslis A, Hasan I, Bourauel C, Bayer S, Stark H, Keilig L. Numerical investigations of the loading behaviour of a prefabricated non-rigid bar system. Ann Anat. 2012 Nov;194(6):538-44. doi: 10.1016/j.aanat.2012.04.004.

14. Ferreira MB, Barão VA, Delben JA, Faverani LP, Hipólito AC, Assunção WG. Non-linear 3D finite element analysis of full-arch implant-supported fixed dentures. Mater Sci Eng C Mater Biol Appl. 2014 May;38:306-14. doi: 10.1016/j.msec.2014.02.021.

15. Bicalho AA, Tantbirojn D, Versluis A, Soares CJ. Effect of occlusal loading and mechanical properties of resin composite on stress generated in posterior restorations. Am J Dent. 2014 Jun;27(3):129-33.

16. Naconecy MM, Geremia T, Cervieri A, Teixeira ER, Shinkai RS. Effect of the number of abutments on biomechanics of Branemark prosthesis with straight and tilted distal implants. J Appl Oral Sci. 2010 Mar-Apr;18(2):178-85. doi: 10.1590/s1678-77572010000200013.

17. Silva-Neto JP, Pimentel MJ, Neves FD, Consani RL, Santos MB. Stress analysis of different configurations of 3 implants to support a fixed prosthesis in an edentulous jaw. Braz Oral Res. 2014;28:67-73. doi: 10.1590/s1806-83242013005000028.

18. Patzelt SB, Bahat O, Reynolds MA, Strub JR. The all-on-four treatment concept: a systematic review. Clin Implant Dent Relat Res. 2014 Dec;16(6):836-55. doi: 10.1111/cid.12068.

19. Hatano N, Yamaguchi M, Yaita T, Ishibashi T, Sennerby L. New approach for immediate prosthetic rehabilitation of the edentulous mandible with three implants: a retrospective study. Clin Oral Implants Res. 2011 Nov;22(11):1265-9. doi: 10.1111/j.1600-0501.2010.02101.x.

20. Teixeira MF, Ramalho SA, de Mattias Sartori IA, Lehmann RB. Finite element analysis of 2 immediate loading systems in edentulous mandible: rigid and semirigid splinting of implants. Implant Dent. 2010 Feb;19(1):39-49. doi: 10.1097/ID.0b013e3181cc7ffc.

21. Martin RB, Burr DB, Sharkey N. Skeletal tissue mechanics. New York: Springer-Verlag; 1998.

22. Duyck J, Van Oosterwyck H, Vander Sloten J, De Cooman M, Puers R, Naert I. Magnitude and distribution of occlusal forces on oral implants supporting fixed prostheses: an in vivo study. Clin Oral Implants Res. 2000 Oct;11(5):465-75. doi: 10.1034/j.1600-0501.2000.011005465.x.

23. Malo P, de Araújo Nobre M, Lopes A, Moss SM, Molina GJ. A longitudinal study of the survival of All-on-4 implants in the mandible with up to 10 years of follow-up. J Am Dent Assoc. 2011 Mar;142(3):310-20. doi: 10.14219/jada.archive.2011.0170.

24. Bhatavadekar NB, Gharpure AS, Balasubramanium N, Scheyer ET. In vitro surface testing methods for dental implants-interpretation and clinical relevance: a review. Compend Contin Educ Dent. 2020 Mar;41(3):e1-e9.

25. dos Santos MB, Caldas RA, Zen BM, Bacchi A, Correr-Sobrinho L. Adaptation of overdenture-bars casted in different metals and their influence on the stress distribution: a laboratory and 3D FEA. J Biomech. 2015 Jan;48(1):8-13. doi: 10.1016/j.jbiomech.2014.11.015.

26. Tribst JPM, Dal Piva AMO, Borges ALS, Bottino MA. Effect of implant number and height on the biomechanics of full arch prosthesis. Braz J Oral Sci. 2018;17:e18222. doi: 10.20396/bjos.v17i0.8653837. 